\title{
Dynamic CGE Model and Simulation Analysis on the Impact of Citizenization of Rural Migrant Workers on the Labor and Capital Markets in China
}

\author{
Qi Wu ${ }^{1,2}$ and Hao Xiao ${ }^{1,2,3}$ \\ ${ }^{1}$ School of Economics and Trade, Hunan University, Changsha, Hunan 410079, China \\ ${ }^{2}$ China-Australian Economic Policy Research Center, Hunan University, Changsha, Hunan 410079, China \\ ${ }^{3}$ Academy of Mathematics and Systems Science, Chinese Academy of Sciences, Beijing 100190, China
}

Correspondence should be addressed to Qi Wu; bluesky_sea8587@126.com

Received 18 April 2014; Revised 8 July 2014; Accepted 10 July 2014; Published 11 August 2014

Academic Editor: Chuangxia Huang

Copyright (C) 2014 Q. Wu and H. Xiao. This is an open access article distributed under the Creative Commons Attribution License, which permits unrestricted use, distribution, and reproduction in any medium, provided the original work is properly cited.

\begin{abstract}
This paper investigates the effect of the policy of citizenization of rural migrant workers on the factor market in a dynamic CGE model, which contains multiple dimensions of labor heterogeneity, a labor-lagged adjustment mechanism, and a dynamic investment mechanism. The simulation results show that changes in supply in the labor market will affect the labor market structure, the relative factor price, and the investment in and the output of industries.
\end{abstract}

\section{Introduction}

There have been large-scale migrations of surplus rural labor to cities in China. Benefiting from the demographic dividend of rural labor transfer, China's economy has maintained a rapid growth rate of $9-10 \%$ per year. With the widening urban-rural income gap [1-3] and aging population [4, 5], China is in a critical period of economic reform and transition. Urbanization that aims to balance urban and rural development is considered the pointcut in further deep reform. The policy of citizenization of rural migrant workers is the essential measure in promoting this urbanization because it can promote rural surplus-labor transfer, break urban and rural employment market segmentation, and solve the periurbanization phenomenon [6,7]. In addition, it can speed up the process of urbanization, expand domestic demand, and boost economic growth [8-10].

Previous relevant research has mainly applied qualitative research techniques to define the concept of citizenization of rural migrant workers $[11,12]$ and to study the obstacles in the process of citizenization of rural migrant workers [13]. Only a few of these studies used quantitative methods to calculate the effect of the policy of citizenization of rural migrant workers, and most focused on the partial equilibrium analysis in analyzing one aspect of the economic effects [14, 15]. However, the citizenization of rural migrant workers is a systematically evolutionary project relating to economic and social aspects. It can affect factor markets through adjusting relative prices and demand in the factor market. To quantify the direct and indirect links between structural change in the labor factor and capital factor, we apply a dynamic computable general equilibrium (CGE) model with detailed sectors and intersectoral linkage information. It is important to analyze the general equilibrium effects of labor-market programs $[16,17]$. Studies on the dynamic CGE model date back to Dixon's MONASH Model [18, 19]. Following that, Mai et al. [20] built a MONASH-style dynamic Computable General Equilibrium model of China (CHINAGEM) to estimate and explain its economic policies. Tran et al. [21] developed a dynamic multiregional computable general equilibrium model of Australia (DIAC-TERM) with special emphasis on the labor market. Meagher et al. [22] analyzed and forecasted the performance of a labor market built around the MONASH general equilibrium model of the Australian economy. Dixon and Jorgenson [23] reviewed options for 
labor market modeling and discussed the wage-forming mechanism and involuntary unemployment in CGE models. Mai [24] developed the Monash-Multi-Country (MMC) model, which is an advanced dynamic CGE model with explicit bilateral investment flows between countries/regions explicitly modeled at an industry level. Xiao [25] built a financial applied general equilibrium (FAGE) model for China. Horridge [26] created the enormous regional model (TERM), which treats each region of a single country as a separate economy. By far, the CGE model framework including labor market, capital market, and regions has been the most systematically established.

A great deal of relevant research has applied the above models to simulate the impact of labor-market and capitalmarket reform, such as structural changes, employment changes, and economic growth [27-30]. However, only a few studies explicitly analyzed the effect of the policy of citizenization of rural migrant workers on the factor market. In this paper, we use the CHINAGEM model to explore and simulate the effects of the policy of citizenization of rural migrant workers in China on economic growth and structural changes in the labor and capital factor markets over a period of ten years from 2010 to 2020.

\section{Overview of the Model}

2.1. CGE Model Description. It is appropriate to use CHINAGEM to simulate the segmented labor market and dynamic investment in China. In this section, we will briefly cover modeling and simulation techniques. According to Mai et al. [20], the production factors include labor force, capital, and land. Under the cost-minimization and profitmaximization assumptions, the production activity of the CGE model is set up as nested CES functions. The top nest is expressed as (1), where $i=1, \ldots, n+2$ are intermediate goods input $(n)$ and primary and other costs, $X_{i j}$ is the effective input, $Z_{j}$ is industry $j^{\prime} s$ activity level, and $A_{j}$ and $A_{i j}$ are technological coefficients.

For each industry $j$, we assume that

$$
\begin{aligned}
& \underset{\substack{\text { Leontief } \\
i=1, \ldots, n+2}}{ }\left\{\frac{X_{i j}}{A_{i j}}\right\}=A_{j} Z_{j}, \quad j^{\prime} s=1, \ldots, h, \\
& \underset{i=1, \ldots, m}{\text { Leontief }\left\{f_{i}\right\}=\operatorname{minimum}}\left\{f_{1}, f_{2}, \ldots, f_{m}\right\} \text {. }
\end{aligned}
$$

Given the units of input, different sources of intermediate goods are combined to provide effective input according to the Armington nest, which is expressed as (2), where $X_{(i s) j}$ is the input of $i$ from sources (domestic and imported) to current production in industry $j, \rho$, and $b$ are parameters, $\rho$ is greater than -1 and not equal to zero, and $b$ is nonnegative.
Consider

$$
\begin{gathered}
X_{i j}=\underset{s=\text { dom,imp }}{\operatorname{CES}}\left\{\frac{X_{(i s) j}}{A_{(i s) j}} ; \rho_{i j}, b_{(i s) j}\right\}, \\
i=1, \ldots, n ; j=1, \ldots, m, \\
\underset{s=\text { dom,imp }}{\operatorname{CES}}\left\{\frac{X_{(i s) j}}{A_{(i s) j}} ; \rho, b_{s}\right\}=\left(\sum_{s} \frac{X_{(i s) j}}{A_{(i s) j}} b_{s}\right)^{-(1 / \rho)} .
\end{gathered}
$$

In the primary nest, labor, capital, and land are combined to form effective input according to (3), in which $X_{(n+1, s) j}$ is the input of primary factor of type $s$ to production industry $j$; $h_{s}, Q_{s}$, and $\kappa$ are parameters; $h_{s}$ is less than 1 and not equal to zero; $Q_{s}$ is positive; and $\sum_{s} Q_{s}=1$. The skill nest in the labor factor is the same CES nest.

Consider

$$
\begin{aligned}
& X_{n+1, j} \\
& =\underset{S=\text { labour,capital,land }}{\mathrm{CRESH}}\left\{\frac{X_{(n+1, s) j}}{A_{(n+1, s) j}} ; h_{(n+1, s) j}, Q_{(n+1, s) j}, K_{(n+1, s) j}\right\}, \\
& \sum_{s}\left(\frac{X_{(n+1, s) j} / A_{(n+1, s) j}}{X_{n+1, j}}\right)^{h_{s}} \frac{Q_{s}}{h_{s}}=\kappa .
\end{aligned}
$$

2.2. Dynamic Flow of the Multivariate Supply of the Labor Submodule in the Segmented Labor Market. To specify labor demand categories, the CGE model updates the multivariate supply of the labor submodule to quantify the multiple dimensions of labor heterogeneity. The multivariate supply of the labor submodule divides the production sectors into agricultural and nonagricultural sectors and sets up the multiple labor transfer matrix on the basis of different household registration, occupation, and skill. The labor categories are then subdivided into five further types: AG, RNAG, RUE, UUSE, and USE. (Agriculture employment (AG), rural nonagriculture employment (RNAG), rural-urban employment (RUE), urban unskilled employment (UUSE), and urban skilled employment (USE).) In consideration of the entrants into the labor market, the submodule subdivides the labor categories into newly added and non-newly added labor force.

The model assumes labor supply from labor category $o$ does not want to be unemployed and prefers to supply to the same industry which they were employed in the previous year. Different categories of labor supply are subject to the Hukou constraint, which indicates that (1) the rural categories (AG, RNAG, RUE, RAGU, and RUU) can only offer rural activities of employment (AG, RNAG, and RUE), (2) the urban categories (UUSE, USE, UU, and NURB) can only make offers of urban activities (UUSE and USE), and (3) the rural new entrants (NRUR) can offer rural as well as urban activities.

Consider

$$
\begin{gathered}
L_{j o, \mathrm{nnl}}^{s^{t}}=L_{j o, \mathrm{nnl}}^{s^{t-1}} * S_{j o, \mathrm{nn} l}^{t-1}, \\
L_{j o, \mathrm{nl}}^{s^{t}}=\delta .
\end{gathered}
$$


$L_{j o, n n l}^{s^{t}}$ is the number of the $o$ type of nonnew labor force in year $t, L_{j o, n l}^{s^{t}}$ is the number of the $o$ type of new labor force in year $t, L_{j o, n n l}^{s^{t-1}}$ is the number of the $o$ type of nonnew labor force in year $t-1, S_{j o, n n l}^{t-1}$ is the proportion of the $o$ type of nonnew labor force in year $t-1$ flow to the $j$ industry in the year $t, S_{j o, \text { nnl }}^{t-1}=0.99$, and $\delta$ is the exogenous parameter.

The dynamic mechanism in the labor market is adjusted dynamically by means of the change in real wages. The lagged adjustment of the labor market is built into the hypothetical conditions: in the short run, wage rigidity and employment elasticity are changeable, and, in the long run, the wage is changeable and the employment rate remains relatively stable. Equation (5) is the dynamic adjustment of labor employment levels. In the first year of the policy, the labor market deviates from full employment. The degree of deviation that is decided by the variable $\partial_{1}$ has been decreasing over time. Equation (6) is the dynamic adjustment of real wages. The degree of realwage deviation increases every year. Therefore, in the initial state of the labor market, there is full employment and the ratio of real wages to expected wages is equal to 1 . Assuming a policy to promote the demand for labor, real wages and employment levels will be higher than expected. The laborsupply curve is a vertical shift until real wages grow and the labor market goes back to the level of full employment.

\section{Consider}

$$
\begin{aligned}
\frac{L_{\mathrm{TOT}}^{t}}{L_{\mathrm{TOT}_{f}}^{t}}-1= & \partial_{1} *\left[\frac{L_{\mathrm{TOT}}^{t-1}}{L_{\mathrm{TOT}_{f}}^{t-1}}-1\right]+F(t) \\
\frac{\mathrm{atw}^{t}}{\mathrm{atw}_{f}^{t}}-1= & {\left[\frac{\mathrm{atw}^{t-1}}{\mathrm{atw}_{f}^{t-1}}-1\right] } \\
& +\partial_{2} *\left[\frac{L_{\mathrm{TOT}}^{t}}{L_{\mathrm{TOT}_{f}}^{t}}-H\left(\frac{\mathrm{atw}^{t-1}}{\mathrm{atw}_{f}^{t-1}}\right)\right]+F_{-} \mathrm{atw}^{t}
\end{aligned}
$$

In (5) and (6), atw is the rate of real wage, $L_{\mathrm{TOT}}$ is employment, $H$ is the long-term labor supply function and is set to equal $1, f$ is the simulation value without policy impact, $\partial_{1}$ and $\partial_{2}$ are the employment adjustment and wage adjustment parameters, and $F$ is the policy shock function, which is given an exogenous value in the year $t$ and set to zero in subsequent years.

In order to achieve dynamic equilibrium in the labor market, it is assumed that wages are variable and there is full employment. After the policy shock, on the basis of exogenous labor supply, the multiple equilibria of the labor market are adjusted by changes in the rate of real wages in the various departments.
Consider

$$
\begin{aligned}
\mathrm{EL}_{j, u b}^{s} & =\mathrm{EF}_{j, w l}^{s_{0}}+\theta_{\mathrm{alsl}} \sum_{\mathrm{a}} \mathrm{tmig}_{a, b, j, l}, \\
\mathrm{EL}_{j, \mathrm{ru}}^{s} & =\mathrm{EF}_{j, w l}^{s_{0}}-\theta_{\mathrm{alal}} \sum_{\mathrm{a}} \sum_{s l} \sum_{i \in u b} \mathrm{tmig}_{a, b, j, s l}, \\
\mathrm{TNL}_{j, l o}^{s} & =\frac{\mathrm{TNL}_{j, l o}^{s_{0}}}{\mathrm{EL}_{j, l o}^{s_{0}}} \mathrm{EL}_{j, l o}^{s}, \\
D_{i, l o}^{d} & =\mathrm{TNL}_{i, l o}^{s} .
\end{aligned}
$$

$\mathrm{EL}_{j, u b}^{s}$ is the effective labor supply for the non-farm sector in the city, $\mathrm{EL}_{j, r u}^{s}$ is the effective labor supply for the nonfarm sector in the rural agricultural sector, $\mathrm{EF}_{j, w l}^{s_{0}}$ is the initial total effective labor supply for various industries, $\theta_{\text {alsl }}$ and $\theta_{\text {alal }}$ are the respective coefficients of effective labor and actual labor, tmig is the total labor force transfer, $\mathrm{TNL}_{j, l o}^{s}$ is the standardized total labor supply of the $o$ type in department $j$, and $D_{i, l o}^{d}$ is the total labor demand of the $o$ type in department $j$.

2.3. The Dynamic Mechanism of Investment. The rate of return is introduced to depict the relationship between capital stock and investment. The model distinguishes various kinds of investment behavior. Equation (8) represents the process of capital accumulation. It reflects that the current capital stock is equal to the previous capital stock plus the current investment and minus the depreciation. Equation (9) is the investment-supply function, where the equilibrium expected rate of return is an inverse logistic function of the proportionate growth of capital stock. Equation (10) defines the actual rates of return under static expectations. It implies that the rate of return decreases as the investment rises. These two equations reveal the relationship between the expected rate of return and investment.

Consider

$$
K_{j, t+1}=K_{j, t}+I_{j, t}-D_{j} * K_{j, t},
$$

$\mathrm{EROR}_{j}$

$$
\begin{aligned}
& =\mathrm{DIS}_{j}+\left\{\mathrm{RORN}_{j}+F_{-} \mathrm{EROR}_{-} J_{i}+F_{-} \mathrm{EROR}\right\} \\
& +\left(\frac{1}{C_{j}}\right) *\left[\operatorname{Ln}\left(K \_G_{j}-K \_G R \_M_{-} N_{j}\right)\right. \\
& -\operatorname{Ln}\left(K \_G R \_M_{-} X_{j}-K \_G_{j}\right) \\
& \text { - Ln }\left(\mathrm{TREND}_{-} K_{j}-K_{-} \mathrm{GR} \_\mathrm{MIN}_{j}\right) \\
& \text { - } \left.\operatorname{Ln}\left(K \_ \text {GR } \_\mathrm{MAX}_{j}-\operatorname{TREND} K_{j}\right)\right] \text {, } \\
& \text { EROR_ST }_{j, t}=-1+\frac{\left[\left(1-T_{t+1}\right) * Q_{j, t+1} / \Pi_{j, t}+\left(1-D_{j}\right)\right]}{\left(1+R_{-} I N T \_P T \_S E_{t}\right)} \text {. }
\end{aligned}
$$

$K$ and $I$ represent capital and investment, respectively, $D$ represents depreciation rate, $\mathrm{DIS}_{j}$ is a measure of 
the difference between the expected rate of return and the equilibrium expected rate of return in industry $j$, EROR and EROR_ST represent an expected rate of return and an expected rate of return under static expectations, RORN is the historically normal rate of return, F_EROR_J and F_EROR allow for vertical shifts in the capital supply curves, $K_{-}$GR is the expected growth of capital stock (equal to the ratio of investment to capital stock), TREND $K$ is the historically normal capital growth rate, $T$ is the tax rate applying to capital income, $Q$ is the rental rate on capital, $\Pi$ is the cost of an extra unit of capital, R_INT_PT_SE is the static expectation of the real post-tax interest rate, and $C$ is a positive parameter.

\section{Simulation Scene Design}

According to China's 12th Five-Year Plan and data from the All-China Federation of Trade Unions (ACFTU) [31], this paper sets up the simulation scene of citizenization of rural migrant workers in phases and dynamically simulates and analyzes the effect of citizenization of rural migrant workers on China's economic growth in the post-international economic crisis era from 2010-2020 (Table 1). China's 12th Five-Year Plan clearly points out that the urbanization rate should grow from $47.5 \%$ to $51.5 \%$ in the years $2011-2015$. To achieve this goal, Han [32] predicted that if the agricultural labor force transfer speed is maintained at $2 \%$ per year from 2006 to 2030, the level of urbanization will increase 0.7-0.8 percentage points annually and the level of urbanization will reach $61 \%$ in the year 2030. An ACFTU (2011) research report suggested that if citizenization of rural migrant workers continues at around 3\% (approximately 300 million people) per year, the urbanization target of China's 12th Five-Year Plan will be achieved. According to the CHINAGEM base period database and ACFTU's data, the paper broke down the policyshock value of the rural labor force to an average annual decrease of $0.65 \%$ and the urban unskilled labor supply to an average annual increase of $1.2 \%$. The simulation of the policy of citizenization of rural migrant workers is implemented in five-year periods starting in 2010.

\section{Simulation Results and Analysis}

According to the CHINAGEM model simulation results, citizenization of rural migrant workers has a significant influence on employment and investment structure. Based on the shock to the labor supply, the labor market adjusts by the mechanism of the labor transition matrix and wages. The change in the labor market affects the rate of return in the capital market and is the primary factor input in the industry. The output and the macroeconomics tend to change as a whole. The transmission mechanism of the simulation shock is provided in Figure 1, the exogenous variables are set outside the model, and the endogenous variables are determined by the model.

4.1. The Labor Employment Effect. From the perspective of total employment (Table 2) in the labor market, it can be seen that the citizenization of rural migrant workers can effectively improve labor force employment in the whole society. From 2011-2015, total employment of the labor force grows rapidly, increasing from $0.11 \%$ to $0.54 \%$. From $2016-$ 2020 , the growth rate of labor force employment declines, but maintains growth momentum. Total labor employment in the whole society increases by $0.05 \%$ in 2020 .

With regard to changes of employment ratios in various industries, it can be seen that primary-industry employment obviously decreases, while employment increases in the secondary and tertiary industries. Growth in the tertiary industry is particularly evident.

On one hand, in terms of labor employment rates in the urban-rural labor market, changes in urban labor force employment are slower than in the rural labor force. In 2020, urban labor force employment increases by $5.88 \%$, while rural labor force employment falls by $6.47 \%$. On the other hand, from the perspective of various types of employment, the supply of and demand form skilled labor and skilled labor increases in urban areas while decreasing in rural areas. In 2020, UUSE employment sees a greater increase than USE at approximately $3.02 \%$ and $2.81 \%$, respectively. RUE, RNAG, and AG employment rates decrease by approximately $2.66 \%$, $2.50 \%$, and $1.60 \%$, respectively (Figure 2).

\subsection{The Effect of Factor Market Structure Adjustment.} Affected by the changes in labor force employment, the prices of the labor factor change correspondingly. As the relative price of this factor changes, the capital accumulation effect promotes growth in the capital and labor markets. In terms of urban and rural labor-factor prices, the wage gap between urban and rural labor narrows. Real wages for the rural labor force continue to rise while real wages for urban labor decrease significantly. In 2020, real wages for AG workers rise by $10.49 \%$, for RANG workers by $9.23 \%$, and for RUE workers by $9.15 \%$, but real wages decrease for UUSE workers by $7.03 \%$ and for USE workers by 7.68\% (Table 3).

Return on capital increases relative to the baseline before it reaches its deviation level in 2017 and decreases in the following years, specifically, by $0.27 \%$ in 2011 , by $0.40 \%$ in 2017 , and by $0.53 \%$ in 2020 . As a result, the amount of capital stock enlarges during the seven-year period during which the policy is implemented and, subsequently, narrows during the last three years. Taking the capital accumulation effect into consideration, the influence of the generalized citizenization process is more obvious.

4.3. The Industry Output Effect. Primary-industry output decreased slightly, especially in animal husbandry and in fishery. The changes in the labor and capital factor markets lead to an increase in output by the secondary and tertiary industries, in which migrant-worker employment is relatively high. In secondary industries, the output of manufacturing increases more obviously because the excess supply of migrant workers is reflected in the decrease in their wage rates. In tertiary industries, the output of construction, education, health, information transmission, storage, postal services, and real estate increases strongly, by $0.32 \%$, $0.21 \%, 0.20 \%, 0.19 \%$, and $0.17 \%$, respectively, mainly because 
TABLE 1: Simulation scene design.

\begin{tabular}{ll}
\hline Type of scene & The simulation scene \\
\hline Baseline & $\begin{array}{l}\text { (1) The total population and the growth of the total workforce are exogenous; (2) the tax rate remains } \\
\text { unchanged on the basis of differences in wage levels and the agricultural labor force can continue to } \\
\text { transfer to nonagricultural sectors; and (3) technology and capital depreciation rates are exogenous } \\
\text { variables. }\end{array}$ \\
\hline $\begin{array}{l}\text { Citizenization of rural } \\
\text { migrant workers }\end{array}$ & $\begin{array}{l}\text { according to the CHINAGEM base period database and ACFTU's data, the paper breaks down the } \\
\text { policy-shock value of the rural labor force to an average annual decrease of } 0.65 \% \text { and the urban unskilled } \\
\text { labor supply to an average annual increase 1.2\%; and (3) other exogenous variables are set to the same } \\
\text { levels as in the baseline scenario. }\end{array}$ \\
\hline
\end{tabular}

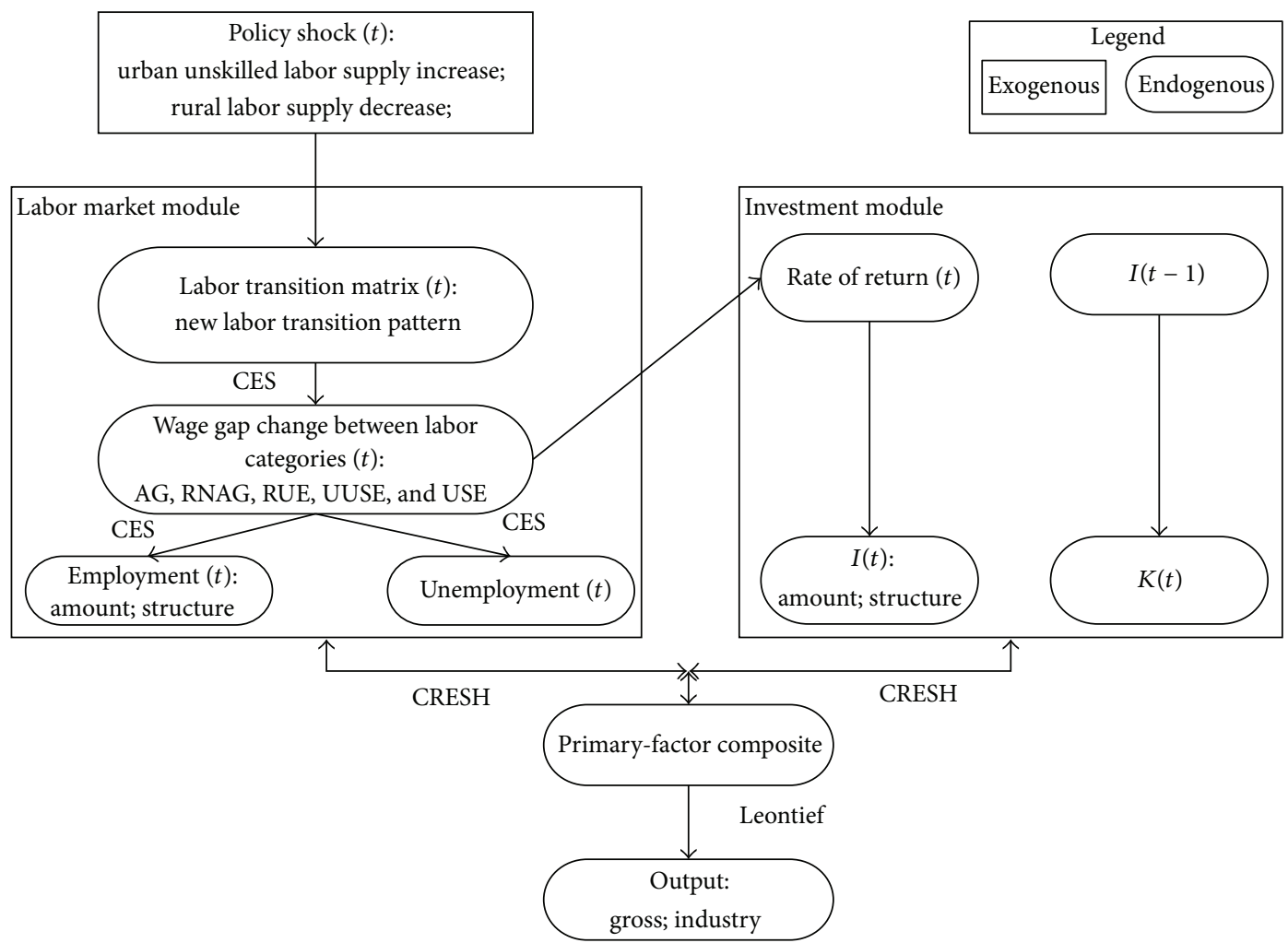

FIGURE 1: The transmission mechanism of the simulation shock.

of investment growth, especially in governmental publicservices spending (Table 4).

\section{Conclusion}

In this paper, we used a dynamic computable general equilibrium model of China to estimate the effect of the policy of citizenization of rural migrant workers. We designed the policy scenarios based on data calculated by the development goals of China's 12th Five-Year Plan. Normally, under the dynamic mechanisms of the labor market and investment, the citizenization of rural migrant workers can expand employment and the scale of investment, accelerate structural adjustment, and boost economic growth in China. The simulation results show that (1) supply changes in the labor market will affect employment rates in the urban-rural labor market and will optimize the urban-rural labor market employment structure, (2) structural changes in the labor factor market will increase the real wages of rural migrant workers and cause a relative rise in capital factor prices, which causes the labor market and capital factor market to achieve a new equilibrium at a higher employment level, and (3) the quantity of the production factor used in each industry will change with the factor-price effect. The output of second and tertiary industries will increase.

There is still much space for improving the model, which requires a more detailed database. It will be worthwhile to classify labor by different education levels and occupation types, to relax the static expectation assumption and to estimate the elasticity of substitution of factors in each industry. 
TABLE 2: The total employment (\% change deviation from baseline).

\begin{tabular}{lccccccccccc}
\hline & 2011 & 2012 & 2013 & 2014 & 2015 & 2016 & 2017 & 2018 & 2019 & 2020 \\
\hline Total employment & $\mathbf{0 . 1 0}$ & $\mathbf{0 . 2 5}$ & $\mathbf{0 . 3 8}$ & $\mathbf{0 . 4 7}$ & $\mathbf{0 . 5 4}$ & $\mathbf{0 . 4 5}$ & $\mathbf{0 . 3 1}$ & $\mathbf{0 . 1 8}$ & $\mathbf{0 . 0 9}$ & $\mathbf{0 . 0 5}$ \\
\hline Primary industry & $\mathbf{0 . 0 1}$ & $-\mathbf{0 . 0 1}$ & $-\mathbf{0 . 1 1}$ & $-\mathbf{0 . 2 6}$ & $-\mathbf{0 . 4 6}$ & $-\mathbf{0 . 7 2}$ & $-\mathbf{0 . 9 5}$ & $-\mathbf{1 . 1 1}$ & $-\mathbf{1 . 2 0}$ & $-\mathbf{1 . 2 3}$ \\
\hline Secondary industry $^{1}$ & $\mathbf{0 . 1 9}$ & $\mathbf{0 . 5 1}$ & $\mathbf{0 . 8 7}$ & $\mathbf{1 . 2 1}$ & $\mathbf{1 . 5 3}$ & $\mathbf{1 . 6 1}$ & $\mathbf{1 . 5 4}$ & $\mathbf{1 . 4 3}$ & $\mathbf{1 . 3 4}$ & $\mathbf{1 . 2 6}$ \\
MotorVhc & 0.35 & 0.81 & 1.22 & 1.57 & 1.86 & 1.78 & 1.57 & 1.39 & 1.28 & 1.21 \\
ElecCommsEqp & 0.30 & 0.77 & 1.30 & 1.83 & 2.34 & 2.49 & 2.43 & 2.30 & 2.17 & 2.05 \\
Meters & 0.21 & 0.62 & 1.16 & 1.76 & 2.38 & 2.73 & 2.84 & 2.83 & 2.76 & 2.67 \\
ToysSportEqp & 0.20 & 0.60 & 1.13 & 1.71 & 2.33 & 2.68 & 2.81 & 2.82 & 2.77 & 2.70 \\
NFerrOre & 0.16 & 0.47 & 0.86 & 1.26 & 1.63 & 1.76 & 1.69 & 1.55 & 1.39 & 1.25 \\
ClothesShoes & 0.16 & 0.45 & 0.82 & 1.23 & 1.63 & 1.83 & 1.87 & 1.84 & 1.79 & 1.75 \\
\hline Tertiary industry & $\mathbf{0 . 2 4}$ & $\mathbf{0 . 6 2}$ & $\mathbf{1 . 0 1}$ & $\mathbf{1 . 3 9}$ & $\mathbf{1 . 7 5}$ & $\mathbf{1 . 8 3}$ & $\mathbf{1 . 7 6}$ & $\mathbf{1 . 6 8}$ & $\mathbf{1 . 6 3}$ & $\mathbf{1 . 5 8}$ \\
Real estate & 0.45 & 1.16 & 1.94 & 2.73 & 3.51 & 3.79 & 3.77 & 3.67 & 3.57 & 3.46 \\
Construction & 0.43 & 0.95 & 1.36 & 1.65 & 1.84 & 1.57 & 1.20 & 0.94 & 0.80 & 0.74 \\
Insurance & 0.29 & 0.79 & 1.37 & 1.97 & 2.57 & 2.83 & 2.86 & 2.82 & 2.77 & 2.71 \\
Tourism & 0.29 & 0.74 & 1.26 & 1.77 & 2.25 & 2.40 & 2.35 & 2.22 & 2.09 & 1.97 \\
Health & 0.27 & 0.71 & 1.22 & 1.75 & 2.27 & 2.49 & 2.52 & 2.50 & 2.46 & 2.43 \\
Education & 0.23 & 0.63 & 1.10 & 1.58 & 2.07 & 2.30 & 2.35 & 2.33 & 2.31 & 2.27 \\
\hline
\end{tabular}

${ }^{1}$ MotorVhc represents automobile manufacturing; ElecCommsEqp represents communications equipment manufacturing; Meters represents instrumentation industry; ToysSportEqp represents toys, sports, and entertainment goods industry; NFerrOre represents non-ferrous metal mining; ClothesShoes represents textile and garment, shoes, and hat manufacturing industry.

TABLE 3: The changes of the factor price in 2010-2020 (\% change deviation from baseline).

\begin{tabular}{ccccccccccccc}
\hline & & 2011 & 2012 & 2013 & 2014 & 2015 & 2016 & 2017 & 2018 & 2019 & 2020 \\
\hline \multirow{2}{*}{ Real wage } & AG & 0.58 & 1.71 & 3.24 & 5.05 & 7.07 & 8.60 & 9.58 & 10.13 & 10.40 & 10.49 \\
& RNAG & 0.54 & 1.47 & 2.70 & 4.17 & 5.80 & 6.99 & 7.87 & 8.50 & 8.94 & 9.23 \\
& RUE & 0.53 & 1.45 & 2.67 & 4.12 & 5.73 & 6.90 & 7.78 & 8.41 & 8.85 & 9.15 \\
& UUSE & -0.64 & -1.67 & -2.89 & -4.23 & -5.61 & -6.34 & -6.71 & -6.89 & -6.99 & -7.03 \\
& USE & -0.39 & -1.28 & -2.46 & -3.82 & -5.28 & -6.40 & -7.03 & -7.38 & -7.58 & -7.68 \\
\hline \multicolumn{2}{c}{ Rate of return } & 0.27 & 0.55 & 0.72 & 0.78 & 0.75 & 0.40 & 0.00 & -0.29 & -0.45 & -0.53 \\
\hline \multicolumn{2}{c}{ Capital stock } & -0.001 & 0.034 & 0.114 & 0.226 & 0.354 & 0.487 & 0.582 & 0.629 & 0.642 & 0.637 \\
\hline
\end{tabular}

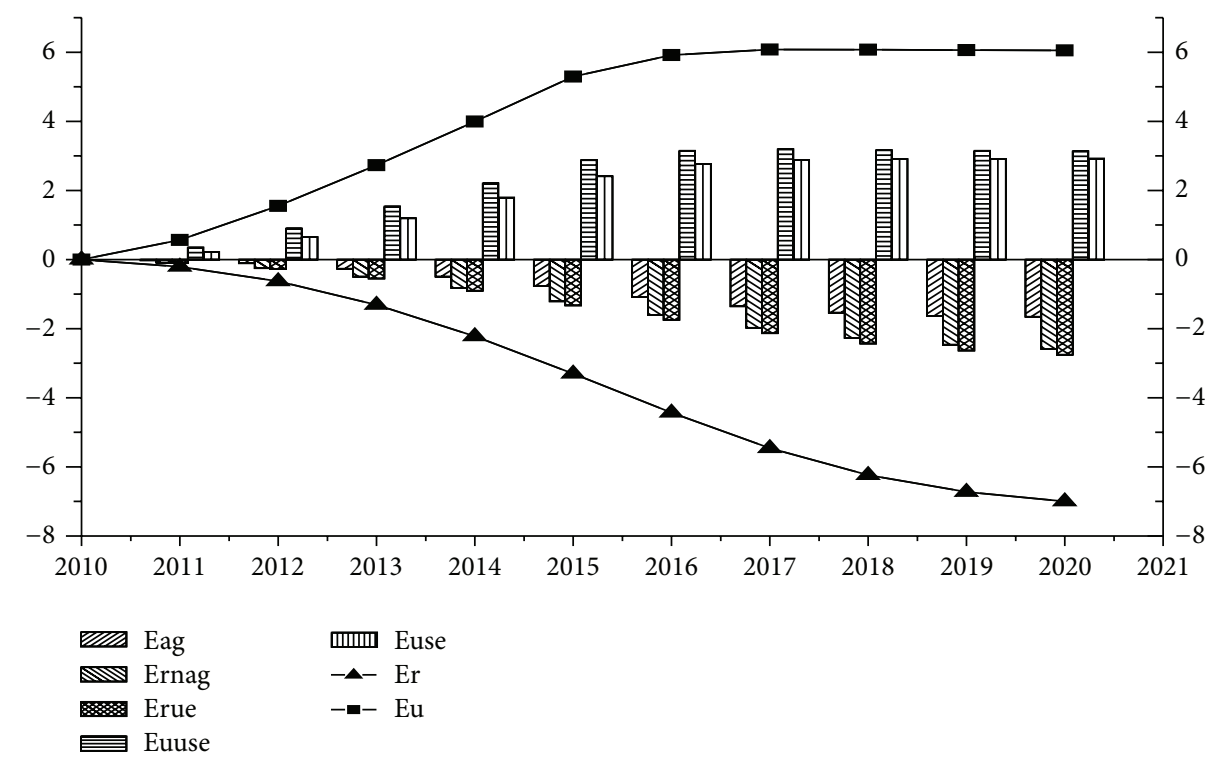

FIGURE 2: The changes of the labor market structure in 2010-2020 (\% change deviation from baseline, $E$ is the employment amount). 
TABLE 4: The output of industry in 2011-2020 (\% change deviation from baseline).

\begin{tabular}{lcccccccccc}
\hline & 2011 & 2012 & 2013 & 2014 & 2015 & 2016 & 2017 & 2018 & 2019 & 2020 \\
\hline Primary industry & $\mathbf{0 . 0 1}$ & $-\mathbf{0 . 0 1}$ & $-\mathbf{0 . 0 8}$ & $-\mathbf{0 . 2 0}$ & $-\mathbf{0 . 3 6}$ & $-\mathbf{0 . 5 7}$ & $-\mathbf{0 . 7 7}$ & $-\mathbf{0 . 9 0}$ & $-\mathbf{0 . 9 8}$ & $-\mathbf{1 . 0 1}$ \\
$\quad$ Farming & 0.02 & 0.02 & -0.01 & -0.08 & -0.18 & -0.34 & -0.50 & -0.61 & -0.68 & -0.71 \\
Forestry & 0.13 & 0.27 & 0.36 & 0.36 & 0.30 & 0.04 & -0.25 & -0.48 & -0.65 & -0.75 \\
Animal husbandry & -0.03 & -0.13 & -0.30 & -0.55 & -0.83 & -1.14 & -1.39 & -1.55 & -1.64 & -1.67 \\
Fishery & -0.03 & -0.10 & -0.23 & -0.41 & -0.63 & -0.86 & -1.05 & -1.18 & -1.24 & -1.26 \\
Other agricultural & 0.06 & 0.17 & 0.29 & 0.40 & 0.52 & 0.54 & 0.51 & 0.48 & 0.47 & 0.48 \\
\hline Secondary industry & $\mathbf{0 . 1 2}$ & $\mathbf{0 . 3 4}$ & $\mathbf{0 . 6 0}$ & $\mathbf{0 . 8 7}$ & $\mathbf{1 . 1 4}$ & $\mathbf{1 . 2 6}$ & $\mathbf{1 . 2 5}$ & $\mathbf{1 . 2 1}$ & $\mathbf{1 . 1 6}$ & $\mathbf{1 . 1 1}$ \\
NonmetalProd $_{\text {FerrMetals }}$ & 0.21 & 0.53 & 0.84 & 1.12 & 1.36 & 1.34 & 1.20 & 1.06 & 0.96 & 0.90 \\
SpecialMac & 0.20 & 0.52 & 0.87 & 1.22 & 1.54 & 1.61 & 1.55 & 1.46 & 1.39 & 1.33 \\
GenpurMac & 0.20 & 0.52 & 0.88 & 1.25 & 1.60 & 1.71 & 1.68 & 1.61 & 1.54 & 1.49 \\
TransEquip & 0.19 & 0.50 & 0.83 & 1.15 & 1.45 & 1.51 & 1.44 & 1.33 & 1.24 & 1.17 \\
\hline Tertiary industry & 0.16 & 0.42 & 0.70 & 0.97 & 1.22 & 1.26 & 1.19 & 1.10 & 1.02 & 0.96 \\
Construction & $\mathbf{0 . 1 7}$ & $\mathbf{0 . 4 4}$ & $\mathbf{0 . 7 5}$ & $\mathbf{1 . 0 7}$ & $\mathbf{1 . 3 7}$ & $\mathbf{1 . 4 7}$ & $\mathbf{1 . 4 5}$ & $\mathbf{1 . 4 0}$ & $\mathbf{1 . 3 6}$ & $\mathbf{1 . 3 4}$ \\
Health $_{\text {Education }}^{0.32}$ & 0.74 & 1.10 & 1.37 & 1.56 & 1.38 & 1.08 & 0.85 & 0.72 & 0.65 \\
ITCompt $^{3}$ & 0.22 & 0.58 & 1.00 & 1.44 & 1.89 & 2.09 & 2.13 & 2.12 & 2.10 & 2.08 \\
Real estate & 0.20 & 0.56 & 0.98 & 1.43 & 1.87 & 2.09 & 2.14 & 2.13 & 2.11 & 2.08 \\
\hline
\end{tabular}

${ }^{2}$ NonmetalProd represents Non-metallic mineral manufacturing; FerrMetals represents ferrous metal smelting and rolling processing industry; SpecialMac represents special equipment manufacturing; GenpurMac represents general equipment manufacturing; TransEquip represents transportation equipment manufacturing.

${ }^{3}$ ITCompt represents information transmission, computer service, and software industry.

\section{Conflict of Interests}

The authors declare that there is no conflict of interests regarding the publication of this paper.

\section{Acknowledgments}

Research is supported by National Natural Science Foundation of China (no. 70873039, no. 71203062, and no. 70925006) and Doctoral Fund of Ministry of Education of China (no. 10YJC790295).

\section{References}

[1] J. Y. Lin, G. Wang, and Y. H. Zhao, "Regional inequality and labor transfer in China," Economic Development and Cultural Change, vol. 52, no. 3, pp. 587-603, 2004.

[2] S. Li and X. M. Yue, "The income gap between urban and rural areas in China is the world's highest," Theoretical Reference, vol. 4, pp. 50-52, 2005.

[3] F. Cai and M. Y. Wang, "Why didn't labor mobility to narrow the income gap between urban and rural areas," Economic Perspectives, vol. 8, pp. 4-10, 2009.

[4] J. Banister, D. E. Bloom, and L. Rosenberg, "Population aging and economic growth in china," PGDAWorking Paper 53, 2010, http://www.hsph.harvard.edu/pgda/WorkingPapers/ 2010/PGDA_WP_53.pdf.

[5] F. Modigliani and S. L. Cao, "The Chinese saving puzzsle and the life-cycle hypothesis," Journal of Economic Literature, vol. 42, no. 1, pp. 145-170, 2004.
[6] A. Watson, "Citizenization of rural migrant workers: the path of solving China's economic imbalances," Chinese Urban Economy, vol. 4, pp. 50-51, 2009.

[7] S. Li, "China's market-oriented reform and income distribution," Journal of Shanghai Finance University, vol. 98, pp. 5-9, 2010.

[8] F. Cai and D. W. Wang, "Sustainability of China's economic growth and labour contribution," Journal of Economic Study, vol. 10, pp. 62-68, 1999.

[9] World Bank, China 2020: Development Challenges in the New Century, World Bank, Washington, DC, USA, 1997.

[10] T. Hertel and F. Zhai, "Labor market distortions, rural-urban inequality and the opening of China's economy," Economic Modelling, vol. 23, no. 1, pp. 76-109, 2006.

[11] C. J. Liu and J. L. Xu, "A study on the second generation peasant w orkers and their citizenization," Population, Resources and Environment, vol. 1, pp. 22-26, 2007.

[12] J. C. Hu, "Studies of citizenization of rural migrant workers," Lanzhou Academic Journal, vol. 8, pp. 91-95, 2010.

[13] K. Huang, "Empirical analysis of the impact on the citizenization of rural migrant workers from urban-rural dual institution," China Population Resource and Environment, vol. 21, pp. 76-81, 2011.

[14] Y. L. Dong, C. J. Liu, and M. Hu, "Urbanization in the context of citizenizing new generation peasant workers," Population Research, vol. 1, pp. 65-73, 2011.

[15] Research Group of Development Research Center of the State Council, "The effect of citizenization of rural migrant workers on the domestic demand and economic growth," Economic Research Journal, vol. 6, pp. 4-16, 2010. 
[16] J. Lise, S. Seitz, and J. Smith, "Equilibrium policy experiments and the evaluation of social programs," NBER Working Paper Series no. 10283, 2004, http://www.nber.org/papers/w10283.

[17] R. Blundell, C. Meghir, M. C. Dias, and J. van Reenen, "Evaluating the employment impact of a mandatory job search program," Journal of the European Economic Association, vol. 2, no. 4, pp. 569-606, 2004.

[18] P. B. Dixon, B. R. Parmenter, J. Sutton, and D. P. Vincent, ORANI: A Multisectoral Model of the Australian Economy, North-Holland, Amsterdam, The Netherlands, 1982.

[19] P. B. Dixon and M. T. Rimmer, Dynamic General Equilibrium Modelling for Forecasting and Policy: A Practical Guide and Documentation of MONASH, North-Holland, Elsevier Science, Amsterdam, The Netherlands, 2002.

[20] Y. H. Mai, P. B. Dixon, and M. T. Rimmer, "CHINAGEM: a monash-styled dynamic CGE model of China," CoPS Working Paper G-201, 2010, http://www.copsmodels.com/ftp/ workpapr/g-201.pdf.

[21] N. Tran, L. Roos, and J. Giesecke, "DIAC-TERM: a multiregional model of the Australian economy with migration detail," CoPS Working Paper no. G-238, 2012, http://www .copsmodels.com/ftp/workpapr/g-238.pdf.

[22] G. A. Meagher, P. D. Adams, and J. M. Horridge, "Applied general equilibrium modeling and labour market forecasting," CoPS Working Paper n o.IP-76, 2000, http://www.copsmodels .com/ftp/workpapr/ip-76.pdf.

[23] P. B. Dixon and D. Jorgenson, Handbook of Computable General Equilibrium Modeling, North-Holland, Amsterdam, The Netherlands, 2011.

[24] Y. H. Mai, "The MONASH-Multi-Country (MMC) model and the investment liberalisation in China's Oil Industry," CoPS Working Paper no. G-150, 2005, http://www.copsmodels .com/ftp/workpapr/g-150.pdf.

[25] J. L. Xiao, "Theoretical structure of the FAGE model," CoPS Working Paper G-198, 2010, http://www.copsmodels .com/ftp/workpapr/g-198.pdf.

[26] M. Horridge, "The TERM model and its data base," CoPS Working Paper no. G-219, 2011, http://www.copsmodels .com/ftp/workpapr/g-219.pdf.

[27] C. Sussangkarn, "Macroeconomic impacts of migrant workers: analyses with a CGE model,” TDRI Quarterly Review, vol. 11, no. 3, pp. 3-11, 1996.

[28] D. G. Johnson, "Can agricultural labour adjustment occur primarily through creation of rural non-farm jobs in China?" Urban Studies, vol. 39, no. 12, pp. 2163-2174, 2002.

[29] Y. H. Mai, X. J. Peng, P. B. Dixon, and M. T. Rimmer, "The effects of facilitating the flow of rural labour to urban employment in China," CoPS Working Paper G-188, 2009, http://www.copsmodels.com/ftp/workpapr/g-188.pdf.

[30] P. B. Dixon, J. Martin, and M. T. Rimmer, "Economy-wide effects of reducing illegal immigrants in U.S. employment," Contemporary Economic Policy, vol. 29, no. 1, pp. 14-30, 2011.

[31] ACFTU, The Report about New Generation of Migrant Workers, Workers' Daily, 2010.

[32] Research Group of Development Research Center of the State Council, "Policy framework and basic thinking of china's rural reform and development in the twelfth five-year plan period," Reform, vol. 5, pp. 5-20, 2010. 


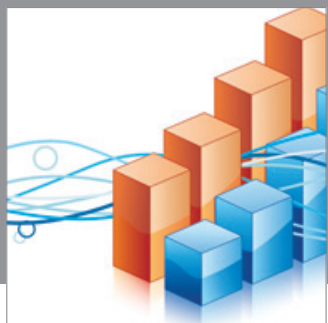

Advances in

Operations Research

mansans

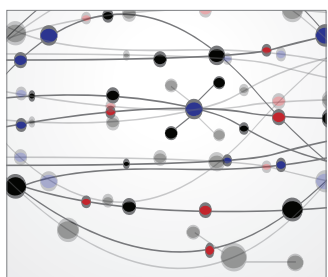

The Scientific World Journal
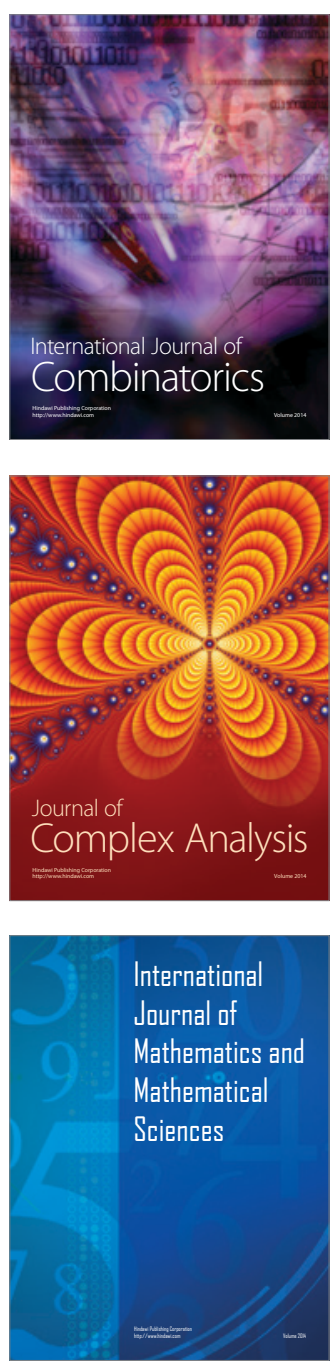
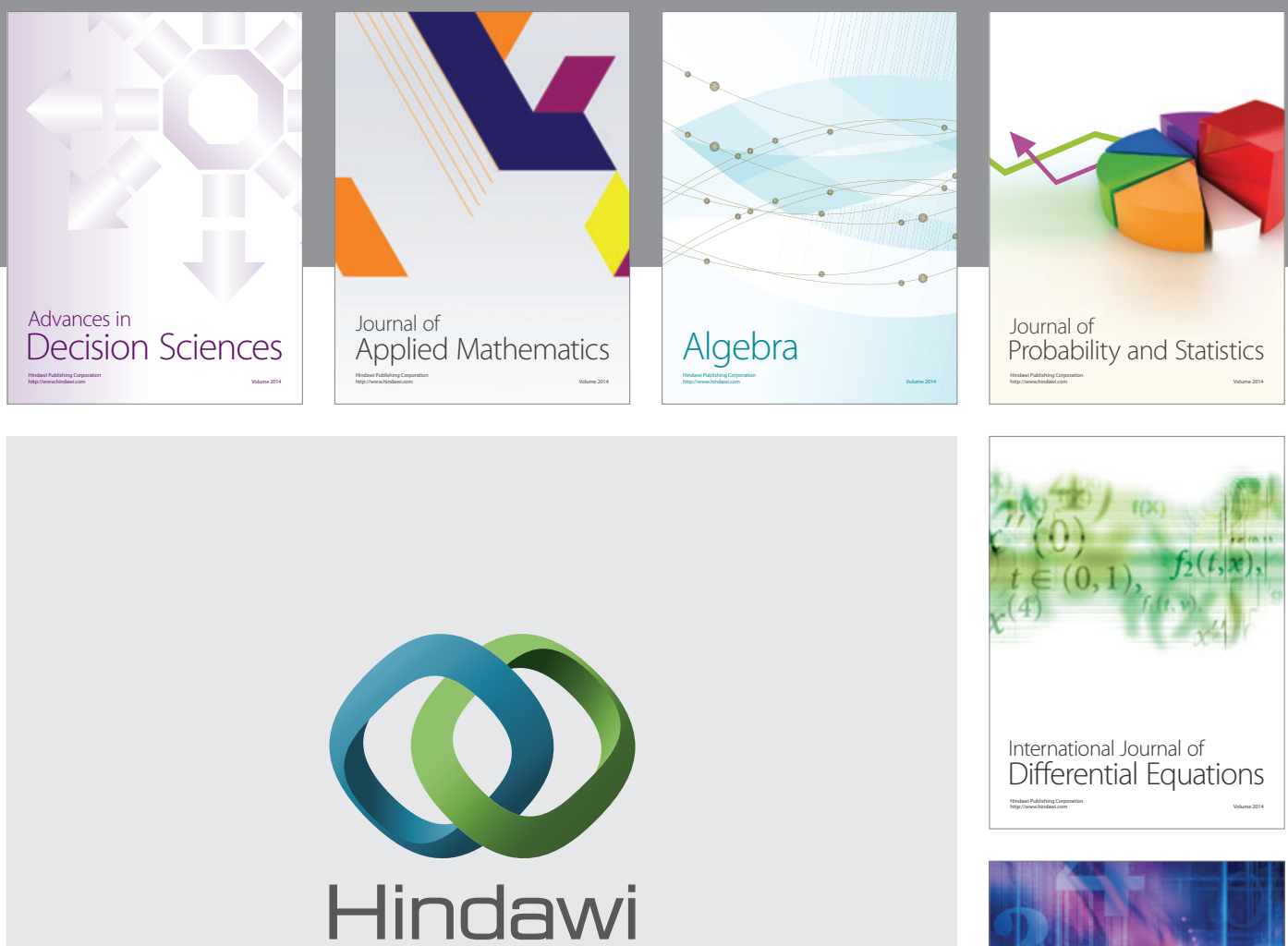

Submit your manuscripts at http://www.hindawi.com
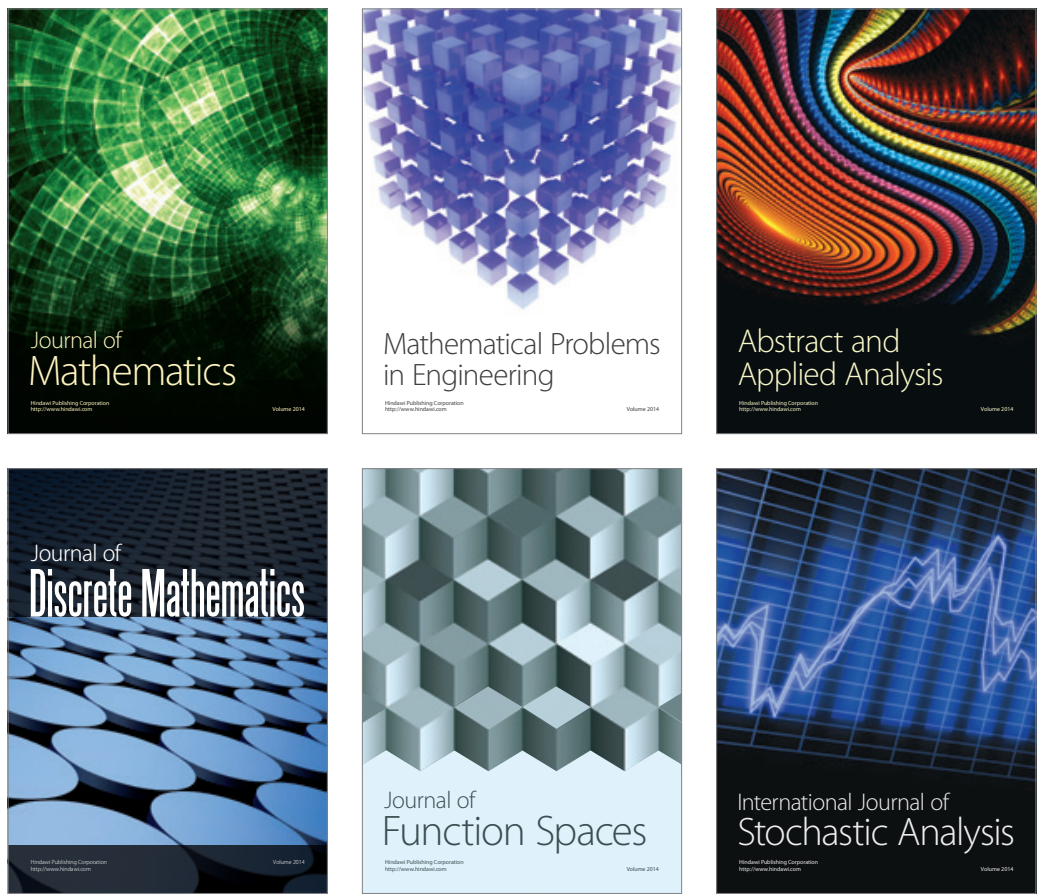

Journal of

Function Spaces

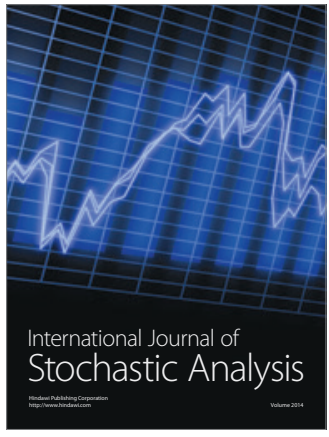

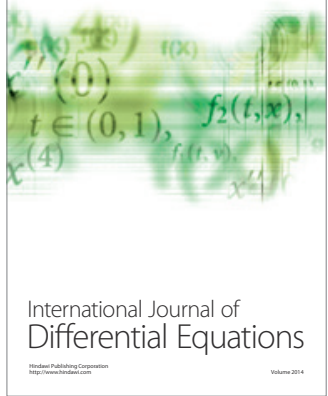
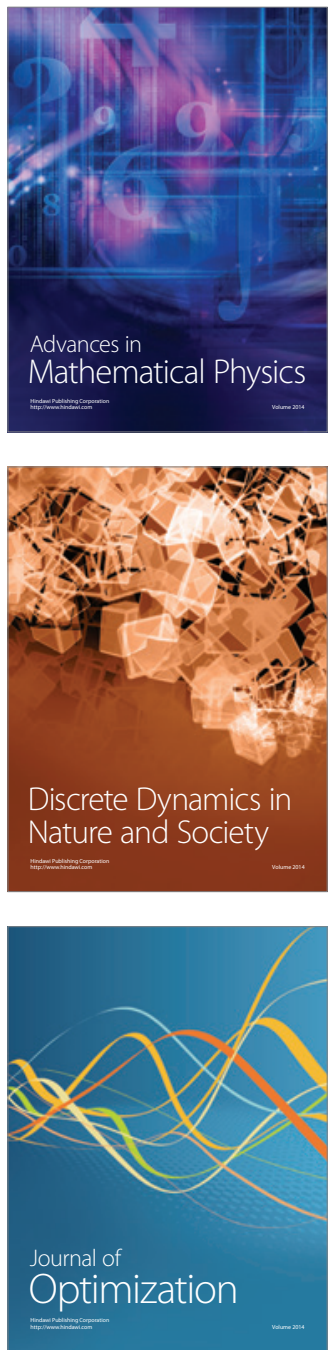